\title{
Multilocus sequence typing of Dientamoeba fragilis identified a major clone with widespread geographical distribution ${ }^{\text {th }}$
}

\author{
Simone M. Cacciò ${ }^{\mathrm{a}, *}$, Anna Rosa Sannella ${ }^{\mathrm{a}}$, Antonella Bruno ${ }^{\mathrm{b}}$, Christen R. Stensvold ${ }^{\mathrm{c}}$, \\ Erica Boarato David ${ }^{\mathrm{d}}$, Semiramis Guimarães ${ }^{\mathrm{d}}$, Elisabetta Manuali ${ }^{\mathrm{e}}$, Chiara Magistrali ${ }^{\mathrm{e}}$, Karim Mahdad ${ }^{\mathrm{f}}$, \\ Miles Beaman ${ }^{\mathrm{f}}$, Roberta Maserati ${ }^{\mathrm{b}}$, Fabio Tosini ${ }^{\mathrm{a}}$, Edoardo Pozio ${ }^{\mathrm{a}}$ \\ a Istituto Superiore di Sanità, Rome, Italy \\ ${ }^{\mathrm{b}}$ Laboratory of Parasitology, Microbiology and Virology, IRCCS San Matteo Hospital Foundation, Pavia, Italy \\ ${ }^{\mathrm{c}}$ Department of Microbiology and Infection Control, Statens Serum Institut, Denmark \\ d Parasitology Department, Institute of Bioscience, São Paulo State University, São Paulo, Brazil \\ e Laboratory of Parasitology, Istituto Zooprofilattico Sperimentale dell'Umbria e delle Marche, Perugia, Italy \\ ${ }^{\mathrm{f}}$ Western Diagnostic Pathology, Myaree, WA, Australia
}

\section{A R T I C L E I N F O}

\section{Article history:}

Received 18 April 2016

Received in revised form 7 July 2016

Accepted 8 July 2016

Available online 21 August 2016

\section{Keywords:}

Dientamoeba fragilis

Human

Genetic markers

Multilocus genotyping

Population structure

\begin{abstract}
A B S T R A C T
The flagellated protozoan Dientamoeba fragilis is often detected in humans with gastrointestinal symptoms, but it is also commonly found in healthy subjects. As for other intestinal protozoa, the hypothesis that genetically dissimilar parasite isolates differ in their ability to cause symptoms has also been raised for $D$. fragilis. To date, only two $D$. fragilis genotypes ( 1 and 2 ) have been described, of which genotype 1 largely predominates worldwide. However, very few markers are available for genotyping studies and therefore the extent of genetic variation among isolates remains largely unknown. Here, we performed metagenomics experiments on two $D$. fragilis-positive stool samples, and identified a number of candidate markers based on sequence similarity to the phylogenetically related species Trichomonas vaginalis. Markers corresponding to structural genes and to genes encoding for proteases were selected for this study, and PCR experiments confirmed their belonging to the $D$. fragilis genome; two previously described markers (small subunit ribosomal DNA and large subunit of RNA polymerase II) were also included. Using this panel of markers, 111 isolates of human origin were genotyped, all of which, except one, belonged to genotype 1 . These isolates had been collected at different times from symptomatic and asymptomatic persons of different age groups in Italy, Denmark, Brazil and Australia. By sequencing approximately $160 \mathrm{~kb}$ from 500 PCR products, a very low level of polymorphism was observed across all the investigated loci, suggesting the existence of a major clone of $D$. fragilis with a widespread geographical distribution.
\end{abstract} (ㄷ) 2016 Australian Society for Parasitology. Published by Elsevier Ltd. All rights reserved.

\section{Introduction}

The non-flagellated flagellate Dientamoeba fragilis has puzzled researchers since its first description about a century ago (Jepps and Dobell, 1918), and many aspects of its biology remain obscure even today (Johnson et al., 2004). The taxonomic position of $D$. fragilis was established about 20 years ago by phylogenetic analysis of the ssrRNA gene, which, in agreement with previous

Note: Nucleotide sequence data reported in this paper are available in the GenBank $^{\mathrm{TM}}$, EMBL and DDBJ databases under the accession numbers KX669659KX669671.

* Corresponding author at: Department of Infectious, Parasitic and Immunomediated Diseases, Istituto Superiore di Sanità, Viale Regina Elena, 299, Rome 00161, Italy. Fax: +3906 49903561 .

E-mail address: simone.caccio@iss.it (S.M. Cacciò). morphological data, demonstrated a close affinity with the trichomonads (Silberman et al., 1996). Further support for this classification has been obtained by a detailed morphological analysis of D. fragilis trophozoites grown in vitro, which showed structures typically found in other trichomonad species such as hydrogenosomes (Banik et al., 2012).

The life cycle of $D$. fragilis is incompletely known: the only wellcharacterised stage is the trophozoite, typically ranging in size from 5 to $15 \mu \mathrm{m}$, which contains one to four nuclei and lacks flagella (Johnson et al., 2004). The presence of a putative cyst stage was reported recently (Munasinghe et al., 2013), and this finding has important implications for our understanding of transmission routes and the epidemiology of infection. Indeed, two transmission routes have been proposed; one involving helminths (mostly pinworms) as mechanical carriers of Dientamoeba (Girginkardeşler 
et al., 2008; Ögren et al., 2013; Röser et al., 2013a, 2015), and another involving direct faecal-oral transmission (Stark et al., 2012; Munasinghe et al., 2013). Evidence in favour of each mechanism was recently reviewed (Barratt et al., 2011; Clark et al., 2014).

The natural host range of the parasite remains incompletely known. Humans have been recognised as a host for a long time; meanwhile, the ability of the parasite to infect non-human hosts has been less explored (Stark et al., 2008). Recent studies demonstrated that pigs are natural hosts of $D$. fragilis (Crotti et al., 2007), and molecular studies showed that pigs harbour a genotype also found in humans (Cacciò et al., 2012), which raises the possibility of a zoonotic transmission of the infection. Other reports are limited to non-human primates such as the Western lowland gorilla (Lankester et al., 2010) and the Ecuadorian mantled howler monkey (Helenbrook et al., 2015), and to rodents, namely house rats in Nigeria (Ogunniyi et al., 2014).

Furthermore, the pathogenic potential of the parasite is still controversial. Some authors suggested the clinical relevance of diagnosing and treating D. fragilis (Barratt et al., 2010; Stark et al., 2010; Banik et al., 2011). Others have argued that the frequent detection of the parasite in stools of healthy individuals suggests it is part of the commensal microbiota (Röser et al., 2013b; Bruijnesteijn van Coppenraet et al., 2015; Krogsgaard et al., 2015), and observed a limited clinical effect of metronidazole treatment of children with gastrointestinal upset (Röser et al., 2014). Meanwhile, and as with other intestinal protozoa, the intragenetic variability has been considered one of the factors possibly influencing the clinical manifestation of $D$. fragilis infection. However, to date only ssrDNA, actin and elongation factor 1-alpha genes have been used to genotype the parasite (Stensvold et al., 2012); therefore, the genetic diversity of this parasite is poorly characterised. Thus far, two genotypes (1 and 2 ) have been described based on ssrDNA analysis, of which genotype 1 largely predominates worldwide (Johnson and Clark, 2000; Windsor et al., 2006).

This study aimed to develop and apply novel markers for studying genetic variation in $D$. fragilis within a large collection of geographically distinct isolates, with a view to describing the level of polymorphism and inferring the population structure of the parasite.

\section{Materials and methods}

\subsection{Selection of candidate markers}

Two human stool samples positive for $D$. fragilis were used for metagenomics experiments. The samples (coded D379 and D1085) originated from the United Kingdom and belonged to genotype 1. Genomic DNA was extracted using the QIAmp Stool DNA Mini Kit (Qiagen, Milan, Italy). Whole genome amplification (WGA) of genomic DNA was performed using a commercial kit (Repli-G Midi, Qiagen) in accordance with the manufacturer's instructions. The amplified DNA was visualised by agarose gel electrophoresis, purified using magnetic beads (MagAttract, Qiagen), and quantified by Nanodrop (ThermoFisher Scientific, Milan, Italy). Genomic DNA was sequenced by the 454 Roche pyrosequencing method. Sequencing was performed by the service provider Macrogen (http://dna.macrogen.com) using short read chemistry. For the D379 and D1085 isolates, a total of 455,798 reads comprising $200 \mathrm{Mbp}$ (average length, $426 \mathrm{bp}$ ) and a total of 320,894 reads comprising $137 \mathrm{Mbp}$ (average length, $457 \mathrm{bp}$ ) were obtained, respectively. Raw sequences were analysed using a metagenomics analysis server (MG-RAST, available at http://metagenomics. anl.gov/). MG-RAST provides taxonomic classification of sequences by interrogating both whole reference genomes and ribosomal databases, and assigns sequences to various taxonomic levels based on the observed sequence similarity. Sequences matching any prokaryotic organism were discarded in order to focus on those that matched eukaryotic genomes or eukaryotic ribosomal sequences. Among the reference eukaryotic genome sequences, the species taxonomically closer to $D$. fragilis is the flagellate Trichomonas vaginalis. All sequences having a T. vaginalis sequence as best match upon BLAST searches at the DNA and protein levels against the National Center for Biotechnology Information (NCBI) database (non-redundant, as at July 2014) were examined. A conservative approach was used to select candidate markers, and only sequences showing $>66 \%$ identity with $T$. vaginalis at the DNA level were retained.

\subsection{Parasite isolates}

The $D$. fragilis-positive stool samples studied are listed in Supplementary Table S1 and were from: (i) stools from 34 outpatients (15 males and 19 females; mean age, 24.1 years (range, 2-81)), referred to the San Matteo Hospital, Pavia, Italy, due to gastrointestinal complaints. Three individuals submitted two separate stool specimens collected at different times. The presence of $D$. fragilis trophozoites was confirmed by microscopy of fresh faecal smears. DNA was extracted using a commercial kit (QIAmp Stool DNA Mini Kit, Qiagen) according to the manufacturer's protocol. (ii) Stools from 25 patients from Denmark (13 males and 12 females; mean age, 20.1 years (range, 4-74)) submitted to parasitological examination due to gastrointestinal complaints, often with a specific request to test for Dientamoeba. DNA was extracted using the NucliSENS easyMag DNA extraction robot (bioMériux Denmark Aps, Herlev, Denmark) (Andersen et al., 2013). The presence of $D$. fragilis DNA was confirmed using real-time PCR (Verweij et al., 2007). (iii) Stools from 30 patients (10 males and 20 females; mean age, 29.2 years (range, 2-85)) referred to a diagnostic laboratory (Western Diagnostic Pathology, Australia) due to gastrointestinal complaints. The most common complaints were abdominal pain and diarrhoea (10 cases), followed by bloating (four cases) and cramping (three cases). Two cases each of vomiting and fever, and single episodes of "altered bowel", nausea, reflux and belching were also noted. Three patients had cleared the infection when tested on a subsequent specimen, but in six other patients, the infection persisted. Samples tested positive for the parasite by a Multiplex Real-Time PCR assay (TIB MOLBIOL LightMix ${ }^{\circledR}$ Modular Dientamoeba fragilis, Roche Diagnostics, Australia). Nucleic acids from stool samples were extracted using the automated MagNA Pure 96 system. (iv) Stools from 19 asymptomatic individuals ( 9 males and 10 females; mean age, 23.1 years (range, 4-64)) living in two Brazilian fishing villages in the State of São Paulo (David et al., 2015). DNA was extracted from stools using a commercial kit (QIAmp Stool DNA Mini Kit, Qiagen) according to the manufacturer's protocol.

It should be noted that the $D$. fragilis-positive stool samples studied here were not selected based on already available genotype information.

\subsection{PCR and sequence analyses}

PCR primers designed using Primer-Blast (http://www.ncbi. nlm.nih.gov/tools/primer-blast/) were developed for nested PCR assays for candidate markers, as well as for the large subunit of RNA polymerase II (Rpb1; Malik et al., 2011). A fragment of the ssrDNA gene was amplified as described previously (Cacciò et al., 2012). Table 1 lists the markers, the proteins putatively encoded, and the primers used for amplification. PCR was performed using $25 \mu \mathrm{L}$ of $2 \mathrm{X}$ GoTaqGreen (Promega, Madison, WI, USA), $10 \mathrm{pmol}$ of each primer, $2.5-5.0 \mu \mathrm{L}$ of DNA, and nuclease-free water up to 
Table 1

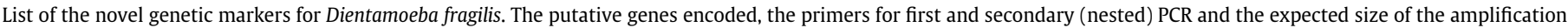
products are indicated.

\begin{tabular}{|c|c|c|c|}
\hline Gene/read name & Forward primer & Reverse primer & $\begin{array}{l}\text { Amplicon } \\
\text { size (bp) }\end{array}$ \\
\hline \multirow[t]{2}{*}{ 14-3-3/HN5VD3C02IP3JE } & $\begin{array}{l}\text { BEF1 5'-GCCCTAAATTTTGATCAAACAGAAC-3' } \\
\text { nested forward }\end{array}$ & $\begin{array}{l}\text { BER1 5'-GACAAGCAAGAACCAGCTAGCAAGGCT-3' } \\
\text { nested reverse }\end{array}$ & 414 \\
\hline & BEFN2 5'-GTTGGTCGTGACAATCTTGCCCGT-3' & Not designed & 236 \\
\hline \multirow[t]{2}{*}{ Laminin A/HN5VD3C02IT0P8 } & $\begin{array}{l}\text { BXF1 5'-CTGGATCGCCTTGTGAATAAT-3' } \\
\text { nested forward }\end{array}$ & $\begin{array}{l}\text { BXR1 5'-ATTTGGTGTTAAGCCAACAG-3' } \\
\text { nested reverse }\end{array}$ & 329 \\
\hline & BXFN2 5'-AAGGTCTTAATACGTGGAGC-3' & BXRN2 5'-TTGCAATTTGGTGTTAAGCC-3' & 266 \\
\hline \multirow[t]{2}{*}{ TKL protein kinase/HN5VD3C02GJVEG } & $\begin{array}{l}\text { CAF1 5'-TGCGATTTTGGATTCTCTAGAAAGG-3' } \\
\text { nested forward }\end{array}$ & $\begin{array}{l}\text { CAR1 5'-TTGGATCACGAGCCCAACAA-3' } \\
\text { nested reverse }\end{array}$ & 300 \\
\hline & CAFN2 5'-CGATTTTGGATTCTCTAGAAAGGCT-3' & CARN2 5'-CTGAGCTGAGACGTTTGAAG-3' & 258 \\
\hline \multirow[t]{2}{*}{$\begin{array}{l}\text { Cathepsin L-like cystein peptidase/ } \\
\text { HN5VD3C02GUAZI }\end{array}$} & $\begin{array}{l}\text { AFF1 5'-GTTGGTTGCGTTGGTTATGGT-3' } \\
\text { nested forward }\end{array}$ & $\begin{array}{l}\text { AFR1 5'-AGCTGGATTGGATGTCTGGAA-3' } \\
\text { nested reverse }\end{array}$ & 348 \\
\hline & AFFN2 5'-TGCGTTGGTTATGGTTCAGAGA-3' & AFRN2 5'-TGGAATGTGTTCATGGTTAAGCG-3' & 326 \\
\hline \multirow[t]{2}{*}{$\begin{array}{l}\text { Clan Sc, family S9, serine peptidase/ } \\
\text { HN5VD3C02G1LCP }\end{array}$} & $\begin{array}{l}\text { FSF1 5'-AGCTGGTGCTGGTGCCTTAT-3' } \\
\text { nested forward }\end{array}$ & $\begin{array}{l}\text { FSR1 5'-ATGTGCTCTGCGATTGCGATA-3' } \\
\text { nested reverse }\end{array}$ & 435 \\
\hline & FSFN2 5'-TGGTGCTGGTGCCTTATCAA-3' & FSRN2 5'-AAGGTAATGGGCACAGCCAA-3' & 357 \\
\hline \multirow[t]{2}{*}{$\begin{array}{l}\text { Clan MH, family M20 metallo-peptidase/ } \\
\text { HN5VD3C02G5WKR }\end{array}$} & $\begin{array}{l}\text { FCF1 5'-GATACTGTTTTCCCACTCCGC-3' } \\
\text { nested forward }\end{array}$ & $\begin{array}{l}\text { FCR1 5'-AGATCGCCAGTGCCTTCTGT-3' } \\
\text { nested reverse }\end{array}$ & 392 \\
\hline & FCFN2 5'-CGCGAGAACTGGAAGAATGTT-3' & FCRN2 5'-GCCAGTGCCTTCTGTGAGG-3' & 379 \\
\hline
\end{tabular}

Table 2

Information on the Dientamoeba fragilis loci, tested isolates and their geographic origin, alleles detected, and availability of genotype 2 information.

\begin{tabular}{|c|c|c|c|c|}
\hline Locus & Number of genotype 1 isolates tested & Geographic origin & Alleles detected in genotype 1 & $\begin{array}{l}\text { Genotype } 2 \\
\text { information }\end{array}$ \\
\hline Laminin A & 78 & $\begin{array}{l}\text { Europe, Australia, } \\
\text { Brazil }\end{array}$ & 1 & No \\
\hline TKL family, protein kinase & 79 & $\begin{array}{l}\text { Europe, Australia, } \\
\text { Brazil }\end{array}$ & 1 & Yes \\
\hline Cathepsin L-like cystein peptidase & 94 & $\begin{array}{l}\text { Europe, Australia, } \\
\text { Brazil }\end{array}$ & 4 & No \\
\hline Clan Sc, family S9, serine peptidase & 76 & $\begin{array}{l}\text { Europe, Australia, } \\
\text { Brazil }\end{array}$ & 1 & No \\
\hline Clan MH, family M20 metallo-peptidase & 101 & $\begin{array}{l}\text { Europe, Australia, } \\
\text { Brazil }\end{array}$ & 2 & Yes \\
\hline Large subunit of RNA polymerase II, RpbI & 49 & Europe, Australia & 3 & No \\
\hline
\end{tabular}

a final volume of $50 \mu \mathrm{L}$. Reactions were performed on a Perkin Elmer 9700 apparatus (Life Technologies, Carlsbad, CA, USA). Aliquots $(5-10 \mu \mathrm{L})$ of PCRs were loaded on $1.5 \%$ agarose gel stained with ethidium bromide. PCR products were purified using spin columns (QiaQuick PCR purification kit, Qiagen) and sequenced along both strands using the ABI PRISM ${ }^{\circledR}$ BigDye $^{\mathrm{TM}}$ Terminator Cycle Sequencing Kit (Life Technologies) according to the manufacturer's instructions. The sequencing reactions were analysed using an ABI PRISM $^{\circledR} 3100$ automatic sequencer (Life Technologies). Chromatograms were edited and assembled using the SeqMan 7.1 software package (DNASTAR, Madison, WI, USA).

\subsection{Population genetic structure}

Each distinct allele observed by sequencing was assigned a unique number; a Multi-Locus Genotype (MLG) was then defined by combining the alleles at each genetic locus. The eBURST software (http://eburst.mlst.net/default.asp) was used to visualise the structure of the $D$. fragilis population. Using this method, the clonal nature of related genotypes and putative "founder" genotypes could be visualised (Feil et al., 2004). The most stringent setting was used, and only single-locus variants (SLVs) differing at one locus only were assigned to the same cluster (table. 2).

\subsection{Data accessibility}

Metagenomics datasets are publicly available at MG-RAST (http://metagenomics.anl.gov/) with the following accession:
MG-RAST ID 4505663.3 and 4505700.3. Results of BLASTn and BLASTx searches are available at https://data.mendely.com (http://dx.doi.org/10.17632/f4kvy5yj4b.1). Nucleotide sequence data reported in this paper are available in the GenBank ${ }^{\mathrm{TM}}$, EMBL and DDBJ databases under the accession numbers KX669659KX669671.

\section{Results}

\subsection{Identification of D. fragilis genetic markers}

A very small fraction $(<1 \%)$ of the DNA sequences generated by pyrosequencing of total DNA from two $D$. fragilis-positive stool samples (D379 and D1085; genotype 1) was classified as being of eukaryotic origin (data not shown). Out of these predicted eukaryotic sequences, we focused on those having significant similarity to T. vaginalis. This procedure identified a few hundred sequences putatively originating from $D$. fragilis, from which we further selected those with the highest similarity at the DNA and protein level. This approach resulted in inclusion of coding sequences only.

Six loci were selected, putatively encoding for a cathepsin L-like cysteine peptidase, a laminin A family protein, a TKL family protein kinase, a peptidase T-like metallo-peptidase, a serine peptidase, and a 14-3-3 protein (Table 1). Using the primers developed for the nested PCR assays, DNAs extracted from the $D$. fragilis-positive stools were tested. Specific amplicons of the expected size were observed for all markers, except for the 14-3-3 protein marker 
gene, supporting a genuine origin of these markers from the parasite's genome (data not shown).

We also designed a nested PCR assay to amplify a $430 \mathrm{bp}$ segment of Rpb1 (Table 1), one of the few available markers for $D$. fragilis. Finally, D. fragilis isolates were also genotyped using ssrDNA.

\subsection{Sequence analysis and population structure}

We investigated sequence polymorphism across the selected loci among $D$. fragilis isolates collected in Italy $(n=37)$, Denmark $(n=25)$, Australia $(n=30)$ and Brazil $(n=19)$.

For the locus encoding a putative cathepsin L-like cysteine peptidase, PCR products from 94 isolates (34 from Italy, 24 from Denmark, 17 from Australia and 19 from Brazil) were sequenced. The amplified fragment encompasses the putative 3 '-end of the cathepsin L-like cysteine peptidase (210 bp), an intergenic sequence (94 bp), and the putative 5'-end of a small Rab GTPase (RabC7; $114 \mathrm{bp})$. When compared with the sequences obtained from metagenomics experiments, only four isolates showed single nucleotide substitutions (SNPs). Specifically, one isolate from Italy (Pv10) and one from Denmark (Den11) shared a single SNP, whereas another isolate from Italy (Pv24) had two SNPs. Finally, one isolate from Italy (Pv19) had two SNPs in the putative intergenic sequence (Supplementary Fig. S1). The single isolate belonging to genotype 2 (Den19) failed to amplify.

For the locus encoding putative Laminin A, PCR products from 78 isolates (11 from Italy, 24 from Denmark, 24 from Australia and 19 from Brazil) were sequenced. All sequences were identical to each other and to the sequences obtained from metagenomics experiments. The single genotype 2 isolate (Den19) failed to amplify.

For the locus encoding a putative TKL family protein kinase, PCR products from 80 isolates (12 from Italy, 25 from Denmark, 24 from Australia and 19 from Brazil) were sequenced. All sequences were identical to each other and to the sequences obtained from metagenomics experiments. The sequence from the genotype 2 isolate (Den19) differed from that of genotype 1 by six synonymous substitutions (Supplementary Fig. S1).

For the locus encoding a putative Clan MH metallo-peptidase, PCR products from 102 isolates (34 from Italy, 25 from Denmark, 24 from Australia and 19 from Brazil) were sequenced. Among the 102 genotype 1 isolates studied, only one isolate from Italy (Pv5) showed a SNP. The sequence from the genotype 2 isolate (Den19) differed from genotype 1 by 27 synonymous substitutions and three non-synonymous substitutions (Supplementary Fig. S1).

For the locus encoding a putative Clan SC serine peptidase, PCR products from 75 isolates (10 from Italy, 22 from Denmark, 24 from Australia and 19 from Brazil) were sequenced. No SNPs were observed among the 76 genotype 1 isolates tested. The single genotype 2 isolate (Den19) failed to amplify.

Lastly, for the RPB1 locus, PCR products from 49 isolates (17 from Italy, 8 from Denmark and 24 from Australia) were sequenced. When compared with a $D$. fragilis sequence (GenBank accession number HM016222), no SNPs were observed in isolates from Denmark, whereas one SNP was shared by four isolates from Italy (Pv 5, 14, 27 and 33) and five isolates from Australia (Au 3, 6, 7,13 and 22), and another SNP was found in a single Italian isolate (Pv 32; Supplementary Fig. S1). Genomic DNA from Brazilian samples was not available at the point when this locus was included in the study. The single genotype 2 isolate (Den19) failed to amplify.

We identified seven MLGs among the D. fragilis isolates, and using the eBURST software, we obtained a typical "star-like" topology with the most common MLG (MLG1) placed centrally and a small number of MLGs connected to it as SLVs (Fig. 1).

\section{Discussion}

In this study, we have produced novel genetic information on $D$. fragilis using metagenomics analysis of total DNA extracted from two $D$. fragilis-positive stool samples. As expected, the overwhelming majority of the DNA sequences reflecting the metagenomics data was of bacterial origin, and less than $1 \%$ originated from eukaryotic organisms (data not shown). By using similarity to sequences from the $T$. vaginalis genome as a selection criterion, markers potentially originating from the $D$. fragilis genome were identified. The candidate $D$. fragilis sequences comprised structural genes, proteases and proteins annotated as hypothetical in the $T$. vaginalis genome (data available at http://dx.doi.org/10.17632/ f4kvy5yj4b.1); intergenic and repetitive sequences could not be identified by this procedure.

PCR assays were designed to verify that candidate markers reflected $D$. fragilis, and confirmed by sequencing amplicons from a panel of isolates previously identified as positive for the parasite. During the course of this study, a transcriptome of in vitro propagated $D$. fragilis trophozoites was developed by a next generation sequencing approach (Barratt et al., 2015), and allowed the confirmation of our candidate markers as truly originating from the parasite's genome.

Taking into account that a recent study (Stensvold et al., 2013) found a very low level of polymorphism in two housekeeping genes (actin and elongation factor 1- $\alpha$ ), additional structural genes and proteases were selected as markers so as to increase the chances of detecting genetic variability among isolates. More than 100 isolates collected in Europe (Italy, Denmark), Brazil and Australia were genotyped. All samples, except one, belonged to genotype 1 . This geographically diverse collection comprised cases of asymptomatic and symptomatic infection in children, adults and the elderly, represented by both genders. We generated a total of $160 \mathrm{~kb}$ of DNA sequences from the selected loci. The result of this sequencing effort was the identification of an extremely low level of polymorphism among genotype 1 isolates. Indeed, genetic variation was absent at loci putatively encoding a TKL family protein kinase, a Clan SC serine peptidase, and a Laminin A. At the remaining loci, limited polymorphism included two alleles at the locus encoding a Clan MH metallo-peptidase, and three alleles at the loci encoding Rpb1 and a cathepsin L-like cysteine peptidase. In contrast, larger genetic variability between genotype 1 and 2 was found, and both synonymous and non-synonymous substitutions were identified at the loci encoding a TKL family protein kinase and a Clan $\mathrm{MH}$ metallo-peptidase (the only two loci that could be amplified from genotype 2). It was not possible to assess

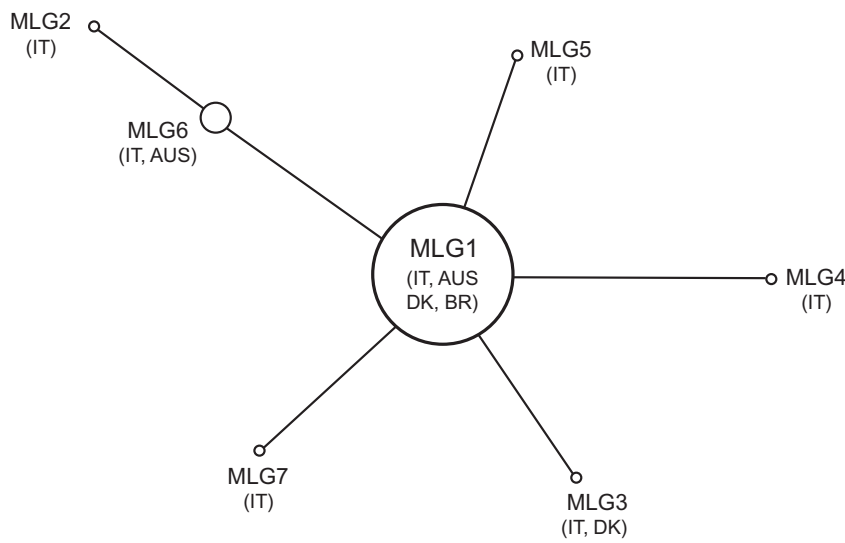

Fig. 1. eBURST analysis of Dientamoeba fragilis multi-locus genotypes (MLGs) from four countries (IT, Italy; DK, Denmark; AUS, Australia; BR, Brazil). Single-locus variants are connected. Sizes of the circles are proportional to MLG abundance. 
intra-genotype 2 genetic variability due to only a single genotype 2-positive sample.

The present multi-locus sequencing data indicates that $D$. fragilis genotype 1 comprises a major clone with a large geographic distribution. Accordingly, the eBURST analysis of MLGs generated a simple diagram, with the most abundant MLG (MLG1) identified as a single founder and a small number of MLGs (MLG2 to MLG7) linked to it as SLVs (Fig. 1). This topology is typical of a clonal complex that diversifies mostly by point mutations. If confirmed by the analysis of other markers, this would suggest that the observed clinical spectrum of infection in humans (symptomatic versus asymptomatic infection) is not influenced by the genetic variability of the parasite. Thus, other factors, including hostderived factors, co-infections with other pathogens, and interactions with the gut microbiota, could play an important role in the absence or presence of intestinal symptoms in subjects harbouring $D$. fragilis.

The very low level of genetic variation observed in $D$. fragilis is remarkable, as most intestinal protists, like those of the genera Cryptosporidium, Giardia and Blastocystis, show remarkable intraspecies variability, even within coding sequences (Ryan and Cacciò, 2013; Nichols et al., 2014). However, it is worth recalling that a very low level of polymorphism was found among isolates of one of the common human-associated Blastocystis subtypes (ST4), in sharp contrast with results for another common subtype, ST3 (Stensvold et al., 2012). It has been suggested that this is the result of a more recent history of human colonization of ST4 compared with ST3 and other STs.

It is still conceivable that the markers selected for this study are particularly conserved or physically linked, and that other markers would have shown more genetic variability. To date, only sequence variability in the ribosomal intergenic transcribed spacers (ITS) has allowed development of a method that distinguishes among different genotype 1 isolates; yet, for this method to gain applicability, it requires a simplified analysis of otherwise complex sequencing chromatograms of ITS amplification products (Bart et al., 2008; Stark et al., 2012). The development of an informative genotyping scheme for $D$. fragilis will probably require the identification of markers such as simple sequence repeats which are usually more polymorphic than coding sequences. In turn, this will require an analysis of parasite isolates at the genome level.

A puzzling observation is the rarity of genotype 2 in humans; here, only one isolate belonged to genotype 2 from more than 100 isolates studied. This very low prevalence suggests that humans are not a natural host of this genotype, and that a zoonotic route involving an unknown animal reservoir may be involved in the rare transmission of this genotype.

In summary, our data study strongly suggest that the population structure of $D$. fragilis is clonal, as is the case for many other bacteria, viruses and parasites (Tibayrenc and Ayala, 2014). Due to its impact on taxonomy and epidemiology of bacterial, viral and eukaryotic pathogens, understanding parasite population structure(s) has been the subject of intense research and controversy (Ramírez and Llewellyn, 2014; Tibayrenc et al., 2015). It should be recalled that clonality does not imply a lack of recombination, but rather a strongly restrained recombination on an evolutionary scale, and that the main consequences of clonality on pathogen population structure are linkage disequilibrium and stable genetic clustering (Tibayrenc et al., 2015). What could be the advantage of clonality for $D$. fragilis? At present, it is difficult to raise an hypothesis, due to a lack of information on how the parasite reproduces and whether a form of sexuality is present. Clonality should permit the proliferation of high-fitness, multi-locus associations and avoid generation of low-fitness recombinants. Whether the major clone of genotype 1 identified in this work has higher fitness requires further investigation.

\section{Acknowledgements}

This work was funded by a grant from the Italian Ministry of Health (Ricerca Corrente RC04/12) and by the DG SANTE of the European Commission.

\section{Appendix A. Supplementary data}

Supplementary data associated with this article can be found, in the online version, at http://dx.doi.org/10.1016/j.ijpara.2016.07. 002.

\section{References}

Andersen, L.O., Röser, D., Nejsum, P., Nielsen, H.V., Stensvold, C.R., 2013. Is supplementary bead beating for DNA extraction from nematode eggs by use of the NucliSENS easyMag protocol necessary? J. Clin. Microbiol. 51, 1345-1347.

Banik, G.R., Barratt, J.L., Marriott, D., Harkness, J., Ellis, J.T. Stark, D., 2011. A casecontrolled study of Dientamoeba fragilis infections in children. Parasitology 138 , 819-823.

Banik, G.R., Birch, D., Stark, D., Ellis, J.T., 2012. A microscopic description and ultrastructural characterisation of Dientamoeba fragilis: an emerging cause of human enteric disease. Int. J. Parasitol. 42, 139-153. http://dx.doi.org/10.1016/j. ijpara.2011.10.010.

Barratt, J.L., Harkness, J. Marriott, D., Ellis, J.T. Stark, D., 2010. A review of Dientamoeba fragilis carriage in humans: Several reasons why this organism should be considered in the diagnosis of gastrointestinal illness. Gut Microbes 2, $3-12$.

Barratt, J.L., Harkness, J., Marriott, D., Ellis, J.T., Stark, D., 2011. The ambiguous life of Dientamoeba fragilis: the need to investigate current hypotheses on transmission. Parasitology 138, 557-572.

Barratt, J.L., Cao, M., Stark, D.J., Ellis, JT, 2015. The transcriptome sequence of Dientamoeba fragilis offers new biological insights on its metabolism, kinome, degradome and potential mechanisms of pathogenicity. Protist 166, 389-408.

Bart, A., van der Heijden, H.M., Greve, S., Speijer, D., Landman, W.J., van Gool, T., 2008. Intragenomic variation in the internal transcribed spacer 1 region of Dientamoeba fragilis as a molecular epidemiological marker. J. Clin. Microbiol. 46, 3270-3275.

Bruijnesteijn van Coppenraet, L.E., Dullaert-de Boer, M., Ruijs, G.J., van der Reijden, W.A., van der Zanden, A.G., Weel, J.F., Schuurs, T.A., 2015. Case-control comparison of bacterial and protozoan microorganisms associated with gastroenteritis: application of molecular detection. Clin. Microbiol. Infect. 21, 592. http://dx.doi.org/10.1016/j.cmi.2015.02.007 e9-e592.

Cacciò, S.M., Sannella, A.R., Manuali, E., Tosini, F., Sensi, M., Crotti, D., Pozio, E., 2012. Pigs as natural hosts of Dientamoeba fragilis genotypes found in humans. Emerg. Infect. Dis. 18, 838-841.

Clark, C.G., Röser, D., Stensvold, C.R., 2014. Transmission of Dientamoeba fragilis: pinworm or cysts? Trends Parasitol. 30, 136-140.

Crotti, D., Sensi, M., Crotti, S., Grelloni, V., Manuali, E., 2007. Dientamoeba fragilis in swine population: a preliminary investigation. Vet. Parasitol. 145, 349-351.

David, E.B., Guimarães, S., de Oliveira, A.P., Goulart de Oliveira-Sequeira, T.C., Nogueira Bittencourt, G., Moraes Nardi, A.R., Martins Ribolla, P.E., Bueno Franco, R.M., Branco, N., Tosini, F., Bella, A., Pozio, E., Cacciò, S.M., 2015. Molecular characterization of intestinal protozoa in two poor communities in the State of São Paulo, Brazil. Parasite Vectors 8, 103. http://dx.doi.org/10.1186/s13071015-0714-8.

Feil, E.J., Li, B.C., Aanensen, D.M., Hanage, W.P., Spratt, B.G., 2004. EBURST: inferring patterns of evolutionary descent among clusters of related bacterial genotypes from multilocus sequence typing data. J. Bacteriol. 186, 1518-1530.

Girginkardeșler, N., Kurt, O., Kilimcioğlu, A.A., Ok, U.Z., 2008. Transmission of Dientamoeba fragilis: evaluation of the role of Enterobius vermicularis. Parasitol. Int. 7, 72-75.

Helenbrook, W.D., Wade, S.E., Shields, W.M., Stehman, S.V., Whipps, C.M., 2015 Gastrointestinal parasites of Ecuadorian mantled howler monkeys (Alouatta palliata aequatorialis) based on fecal analysis. J. Parasitol. 101, 341-350. http:// dx.doi.org/10.1645/13-356.

Jepps, M.W., Dobell, C., 1918. Dientamoeba fragilis n.g., n.sp.: a new intestinal ameba from man. Parasitology 10, 352-367.

Johnson, J.A., Clark, C.G., 2000. Cryptic genetic diversity in Dientamoeba fragilis. J. Clin. Microbiol. 38, 4653-4654.

Johnson, E.H., Windsor, J.J., Clark, C.G., 2004. Emerging from obscurity: biological, clinical, and diagnostic aspects of Dientamoeba fragilis. Clin. Microbiol. Rev. 17, 553-570.

Krogsgaard, L.R., Engsbro, A.L., Stensvold, C.R., Nielsen, H.V., Bytzer, P., 2015. The prevalence of intestinal parasites is not greater among individuals with irritable bowel syndrome: a population-based case-control study. Clin. Gastroenterol. Hepatol. 13, 507-513. http://dx.doi.org/10.1016/j.cgh.2014.07.065.

Lankester, F., Kiyang, J.A., Bailey, W., Unwin, S., 2010. Dientamoeba fragilis: initial evidence of pathogenicity in the western lowland gorilla (Gorilla gorilla gorilla). J. Zool. Wildl. Med. 41, 350-352. 
Malik, S.B., Brochu, C.D., Bilic, I., Yuan, J., Hess, M., Logsdon Jr, J.M., Carlton, J.M., 2011. Phylogeny of parasitic parabasalia and free-living relatives inferred from conventional markers vs. Rpb1, a single-copy gene. PLoS One 6. http://dx.doi. org/10.1371/journal.pone.0020774 e20774.

Munasinghe, V.S., Vella, N.G., Ellis, J.T. Windsor, P.A. Stark, D., 2013. Cyst formation and faecal-oral transmission of Dientamoeba fragilis-the missing link in the life cycle of an emerging pathogen. Int. J. Parasitol. 43, 879-883.

Nichols, G.L., Chalmers, R.M., Hadfield, S.J., 2014. Molecular epidemiology of human cryptosporidiosis. In: Cacciò, S.M., Widmer, G. (Eds.), Cryptosporidium: Parasite and Disease. Springer, New York, USA, pp. 81-148.

Ögren, J., Dienus, O., Löfgren, S., Iveroth, P., Matussek, A., 2013. Dientamoeba fragilis DNA detection in Enterobius vermicularis eggs. Pathog. Dis. 69, 157-158.

Ogunniyi, T., Balogun, H., Shasanya, B., 2014. Ectoparasites and endoparasites of peridomestic house-rats in ile-ife, Nigeria and implication on human health. Iran. J. Parasitol. 9, 134-140.

Ramírez, J.D., Llewellyn, M.S., 2014. Reproductive clonality in protozoan pathogenstruth or artefact? Mol. Ecol. 23, 4195-4202. http://dx.doi.org/10.1111/ mec. 12872.

Röser, D., Nejsum, P., Carlsgart, A.J., Nielsen, H.V., Stensvold, C.R., 2013a. DNA of Dientamoeba fragilis detected within surface-sterilized eggs of Enterobius vermicularis. Exp. Parasitol. 133, 57-61. http://dx.doi.org/10.1016/ j.exppara.2012.10.009.

Röser, D., Simonsen, J., Nielsen, H.V., Stensvold, C.R., Mølbak, K., 2013b. Dientamoeba fragilis in Denmark: epidemiological experience derived from four years of routine real-time PCR. Eur. J. Clin. Microbiol. Infect. Dis. 32, 1010-1303. http:// dx.doi.org/10.1007/s10096- 013-1880-2.

Röser, D., Simonsen, J., Stensvold, C.R., Olsen, K.E., Bytzer, P., Nielsen, H.V., Mølbak, K., 2014. Metronidazole therapy for treating dientamoebiasis in children is not associated with better clinical outcomes: a randomized, double-blinded and placebo-controlled clinical trial. Clin. Infect. Dis. 58, 1692-1699.

Röser, D., Simonsen, J., Nielsen, H.V., Stensvold, C.R., Mølbak, K., 2015. History of antimicrobial use and the risk of Dientamoeba fragilis infection. Eur. J. Clin.
Microbiol. Infect. Dis. 34, 1145-1151. http://dx.doi.org/10.1007/s10096-0152334-9.

Ryan, U., Cacciò, S.M., 2013. Zoonotic potential of Giardia. Int. J. Parasitol. 43, 943-956. Silberman, J.D., Clark, C.G., Sogin, M.L., 1996. Dientamoeba fragilis shares a recent common evolutionary history with the trichomonads. Mol. Biochem. Parasitol. 76, 311-314.

Stark, D., Phillips, O., Peckett, D., Munro, U., Marriott, D., Harkness, J., Ellis, J., 2008. Gorillas are a host for Dientamoeba fragilis: an update on the life cycle and host distribution. Vet. Parasitol. 151, 21-26.

Stark, D., Barratt, J., Roberts, T., Marriott, D., Harkness, J., Ellis, J., 2010. A review of the clinical presentation of dientamoebiasis. Am. J. Trop. Med. Hyg. 82, 614619.

Stark, D., Roberts, T., Marriott, D., Harkness, J., Ellis, J.T., 2012. Detection and transmission of Dientamoeba fragilis from environmental and household samples. Am. J. Trop. Med. Hyg. 86, 233-236.

Stensvold, C.R., Alfellani, M., Clark, C.G., 2012. Levels of genetic diversity vary dramatically between Blastocystis subtypes. Infect. Genet. Evol. 12, 263-273. http://dx.doi.org/10.1016/j.meegid.2011.11.002.

Stensvold, C.R., Clark, C.G., Roser, D., 2013. Limited intra-genetic diversity in Dientamoeba fragilis housekeeping genes. Infect. Genet. Evol. 18, 284-286.

Tibayrenc, M., Ayala, F.J., 2014. Cryptosporidium, Giardia, Cryptococcus, Pneumocystis genetic variability: cryptic biological species or clonal near-clades? PLoS Pathog. 10. http://dx.doi.org/10.1371/journal.ppat.1003908 e1003908.

Tibayrenc, M., Avise, J.C., Ayala, F.J., 2015. In the light of evolution IX: Clonal reproduction: Alternatives to sex. Proc. Natl. Acad. Sci. U.S.A. 112, 8824-8826 http://dx.doi.org/10.1073/pnas.1508087112.

Verweij, J.J., Mulder, B., Poell, B., van Middelkoop, D., Brienen, E.A., van Lieshout, L. 2007. Real-time PCR for the detection of Dientamoeba fragilis in fecal samples. Mol. Cell. Probes. 21, 400-404.

Windsor, J.J., Macfarlane, L., Clark, C.G., 2006. Internal transcribed spacer dimorphism and diversity in Dientamoeba fragilis. J. Eukaryot. Microbiol. 53, 188-192. 